\title{
Qualitative and quantitative analyses of (pro)renin receptor in the medium of cultured human umbilical vein endothelial cells
}

\author{
Kazal Boron Biswas ${ }^{1}$, AHM Nurun $\mathrm{Nabi}^{2}$, Yoshie Arai ${ }^{2}$, Tsutomu Nakagawa ${ }^{1,2}$, Akio Ebihara ${ }^{1,2}$, \\ Atsuhiro Ichihara ${ }^{3}$, Tadashi Inagami ${ }^{4}$ and Fumiaki Suzuki ${ }^{1,2}$
}

A 30-kDa protein in the medium of cultured human umbilical vein endothelial cells (HUVECs) was identified as (pro)renin receptor, (P)RR, by western blot analysis using anti-human (P)RR antibodies. The protein bound recombinant human prorenin with a $K_{\mathrm{D}}$ of $4.0 \mathrm{nmolI}^{-1}$ and activated prorenin. These observations suggest the presence of soluble (P)RR, $s(P) R R$, in the medium of cultured HUVECs. For quantification of the $s(P) R R$ in the medium, an enzyme-linked immunosorbent assay (ELISA) was established. The quantitative range of the ELISA was validated over a nominal range of 7.5-300 $\mathrm{pmolI}^{-1}$ in the wells of a microtiter plate. The assay system showed good linearity $\left(r^{2}=0.99\right)$ with interassay $(5.8-9.7 \%)$ and intraassay $(2.1-7.0 \%)$ precision. Using this method, the concentration of $s(P) R R$ in the culture medium of HUVECs was measured to be $32 \mathrm{pmol}^{-1}$. Therefore, these results show qualitative and quantitative evidence that prorenin can be activated after binding to s(P)RR secreted from cultured HUVECs. Hypertension Research (2011) 34, 735-739; doi:10.1038/hr.2011.26; published online 17 March 2011

Keywords: prorenin; (pro)renin receptor; sandwich ELISA; soluble (P)RR

\section{INTRODUCTION}

The (pro)renin receptor ((P)RR), a new member of the renin-angiotensin system with 334 amino-acid residues $(35 \mathrm{kDa})$ and a single transmembrane domain, specifically binds to renin and prorenin on the cell membrane. ${ }^{1,2}$ Catalytic activity of renin increases several fold after binding to this receptor. ${ }^{1,3}$ Also, prorenin, a physiologically inactive precursor molecule, shows renin activity after binding to $(\mathrm{P}) \mathrm{RR}^{1,3-5}$ Functional (P)RR on the membrane is able to induce signal transduction cascades after ligand binding via receptor phosphorylation and activation of the mitogen-activated protein kinases ERK1/2. ${ }^{1,6}$ This receptor is involved in pathological events, such as diabetic retinopathy, nephropathy and hypertension. ${ }^{7-9}$ Overexpressed (P)RR in smooth muscle cells causes elevated blood pressure and increased heart rate, ${ }^{10}$ and glomerulosclerosis and proteinuria have been reported in transgenic models in which (P)RR is overexpressed. ${ }^{11}$ Mutation of the $(P) R R$ gene is associated with X-linked mental retardation in humans. ${ }^{12}$

We have reported the expression and purification of full-length rat (P)RR using a baculovirus expression system. ${ }^{13,14}$ Purified rat (P)RR could bind to rat renin and its inactive form, prorenin. Full-length (P)RR has also been expressed in the silkworm and found to bind renin and prorenin. ${ }^{15}$ Receptor-bound forms of renin and prorenin perform catalytic activities by generating angiotensin-I (Ang-I) from angiotensinogen. Recently, furin has been reported to cleave intact
(P)RR to secrete a soluble $(\mathrm{P}) \mathrm{RR}(\mathrm{s}(\mathrm{P}) \mathrm{RR}, 28 \mathrm{kDa})$ into human plasma and into cell culture medium. ${ }^{2}$ So far, only the existence of $\mathrm{s}(\mathrm{P}) \mathrm{RR}$ (full-length and shed forms) and the interaction properties of soluble full-length $(\mathrm{P}) \mathrm{RR}$ with renin and prorenin have been reported. However, the properties of prorenin interacting with shed $s(\mathrm{P}) \mathrm{RR}$ have not yet been revealed. Determination of the concentration of $s(P) R R$ in cell culture medium is required to study the pathological involvement of $(\mathrm{P}) \mathrm{RR}$ in greater detail, considering the cellular and pathological responses mediated by $(\mathrm{P}) \mathrm{RR}$, prorenin-(P)RR complexes and prorenin concentration in the plasma (which is 10 times higher than that of mature renin). Therefore, in this study, $s(P) R R$ was identified in the medium of cultured human umbilical vein endothelial cells (HUVECs), its interaction properties with human recombinant prorenin were evaluated and an enzyme-linked immunosorbent assay (ELISA) system was established for quantitative analysis of $s(\mathrm{P}) \mathrm{RR}$ levels.

\section{METHODS}

Experimental design

The culture medium from HUVECs was tested for the presence of shed s(P)RR, which was anticipated based on previous studies, using western blotting with antihuman (P)RR antibodies and surface plasmon resonance in a BIAcore (BIAcore 2000, Uppsala, Sweden) assay system. Finally, a sandwich ELISA was established to measure the concentration of $s(\mathrm{P}) \mathrm{RR}$ in the medium of cultured HUVECs.

\footnotetext{
${ }^{1}$ Laboratory of Animal Biochemistry, United Graduate School of Agricultural Science, Gifu University, Gifu, Japan; ${ }^{2}$ Faculty of Applied Biological Sciences, Gifu University, Gifu, Japan; ${ }^{3}$ Department of Internal Medicine, Keio University School of Medicine, Tokyo, Japan and ${ }^{4}$ Department of Biochemistry, Vanderbilt University School of Medicine, Nashville, TN, USA Correspondence: Professor F Suzuki, Laboratory of Animal Biochemistry, United Graduate School of Agricultural Science and Faculty of Applied Biological Sciences, Gifu University, 1-1 Yanagido, 501-1193 Gifu, Japan.

E-mail: aob3073@gifu-u.ac.jp

Received 15 November 2010; revised 21 December 2010; accepted 1 January 2011; published online 17 March 2011
} 
Recently, we were able to synthesize (P)RR lacking the transmembrane sequence and tagged with six histidine residues at the $\mathrm{C}$ terminus in vitro using wheat germ lysate. This synthesized protein showed properties similar to those of full-length $(\mathrm{P}) \mathrm{RR}$ expressed on the cell membrane, binding to both recombinant human renin and prorenin with affinities in the nanomolar range. ${ }^{16}$ The molecular size of this receptor, $32.5 \mathrm{kDa}$, was confirmed by SDS-polyacrylamide gel electrophoresis and western blot analysis using several anti-(P)RR antibodies designed from various epitope sequences. To standardize the sandwich ELISA, recombinant $(\mathrm{P}) \mathrm{RR}$ was used at different concentrations. The anti-(P)RR antibodies that recognized $(\mathrm{P}) \mathrm{RR}$ on western blots were used in the ELISA protocol. Finally, this ELISA protocol was successfully used to measure the concentration of (P)RR in HUVEC culture medium.

\section{Design and synthesis of anti-(P)RR antibodies}

Anti-human (P)RR antibodies, labeled as $\alpha$-human renin $\mathrm{R}$ polyclonal antibody (developed in goats), was purchased from R\&D systems (Minneapolis, $\mathrm{MN}$, USA), and polyclonal $\alpha$-human (P)RR antibodies designed against the antigenic sequences $\mathrm{E}^{221}$ IGKRYGEDSEQFRD $^{235}$ and $\mathrm{S}^{237}$ KILVDALQKFADD $^{250}$ (close to the $\mathrm{N}$ terminus of the transmembrane region of the receptor; denoted as anti-221/235 and anti-237/250, respectively) were produced in rabbits.

\section{HUVECs and $s(\mathrm{P}) \mathrm{RR}$}

Recently, Leckie and Bottrill ${ }^{17}$ reported the presence of (P)RR in HUVEC extract. Furthermore, Uraoka et al. ${ }^{18}$ reported the expression of (P)RR on the membrane of HUVECs that induced ERK activation after binding to prorenin. Our previous studies have also demonstrated the properties of (P)RR binding to its ligands, renin and prorenin, using overexpressed (P)RR on the membrane of COS-7 cells and recombinant (P)RR synthesized in vitro. In this study, we focused on qualitative and quantitative analyses of the soluble form of (P)RR. For this reason, the culture medium from HUVECs (passage 3, maintained in $2 \%$ fetal bovine serum with essential endothelial growth factors, $0.1 \%$ heparin, $1 \%$ ascorbic acid, $0.04 \%$ hydrocortisone and $0.1 \%$ gentamicin/amphotericin1000 ) was harvested after the cells were seeded in a $75-\mathrm{cm}^{2}$ tissue culture flask at $75-85 \%$ confluence. The collected medium was concentrated 20 -fold using polyethylene glycol. The concentrated medium was treated with ammonium sulfate, allowed to precipitate, and resuspended in phosphate-buffered saline. For optimum purification of human (P)RR, $0.1 \%$ of a mild detergent, Brij35 (Sigma-Aldrich, St Louis, MO, USA), was used to avoid precipitation of the protein. Thus, the presence of $(\mathrm{P}) \mathrm{RR}$ in the medium was verified via SDSpolyacrylamide gel electrophoresis and western blotting. Briefly, for the western blot analysis, anti-237/250 antibody (1:1000, Qiagen, Hilden, Germany) from rabbit was used as the primary antibody, and the secondary antibody was antirabbit IgG conjugated to horseradish peroxidase (1:1000, GE healthcare, Buckinghamshire, UK).

\section{Synthesis and purification of recombinant $(\mathrm{P}) \mathrm{RR}$ and prorenin} Human (P)RR (containing 292 amino acids (N17-N308), with six histidine residues at the $\mathrm{C}$ terminus and lacking the transmembrane sequence) was synthesized in a cell-free in vitro system based on wheat germ lysate according to a previously described method..$^{5,16,19,20}$ Briefly, complementary DNA encoding the desired protein was amplified by PCR using primers with the restriction sites for NotI and XhoI. The forward and reverse primers were $5^{\prime}$-TTTGCGG CCGCAATGAATTTAGCATATTAAGATCGC- ${ }^{\prime}$ and $5^{\prime}$-TTTCTCGAGGTTGA AAACCACCGAATACT-3', respectively. Following PCR purification, the product was digested with NotI and XhoI, and then inserted into the pIVEX 1.3WG vector. The vector containing the insert was expressed in a continuous exchange cell-free in vitro translation system based on wheat germ lysate using the RTS 500 Wheat Germ CECF kit according to the manufacturer's instructions (Roche Diagnostics GmbH, Mannheim, Germany). The receptor was purified by affinity chromatography using a His-Trap column (GE healthcare), and its presence was confirmed by SDS-polyacrylamide gel electrophoresis and western blot analysis using an anti-His tag antibody and an antibody directed against an antigenic sequence $\left(\mathrm{E}^{221}\right.$ IGKRYGEDSEQFRD ${ }^{235}$ ) designed from the nearby $\mathrm{N}$-terminal sequence of the transmembrane domain (Figure 2a, lane 2). The molecular size of $(\mathrm{P}) \mathrm{RR}$ was estimated to be $32.5 \mathrm{kDa}$ because the construct lacks the transmembrane domain. The ability of recombinant $(\mathrm{P}) \mathrm{RR}$ to bind its ligands, renin and prorenin, has been evaluated previously in real time using surface plasmon resonance in a BIAcore assay system. ${ }^{16,19}$

Chinese hamster ovary cells harboring complementary DNA coding for human prorenin (383 amino-acid residues with a decahistidine at the $\mathrm{C}$ terminus) were maintained in conditioned Dulbecco's modified Eagle's medium according to the method described by Nakagawa et al. ${ }^{21}$ SDS-polyacrylamide gel electrophoresis and western blot analysis were used to determine the molecular size of prorenin. The secreted crude preparation of prorenin in the culture medium was purified as described above. ${ }^{21}$

\section{Real-time binding of prorenin to $s(P) R R$ secreted by cultured HUVECs}

The anti-221/235 antibody was immobilized on a carboxymethyl 5 sensor chip via amine coupling, according to our previous protocol, to determine proteinprotein interaction in real time with a BIAcore assay system. ${ }^{19}$ The anti-237/250 antibody was immobilized using the same protocol. Approximately $0.5 \mathrm{ng}$ of antibodies per square millimeter of surface area was immobilized. Resonance units indicate the binding quantities of the analytes. The cultured HUVEC medium was flown through the system at $10 \mu \mathrm{min}^{-1}$, and binding of $\mathrm{s}(\mathrm{P}) \mathrm{RR}$ to the immobilized antibodies was indicated by resonance signals. The binding signals from recombinant $(\mathrm{P}) \mathrm{RR}$ were used as a positive response control, as described previously. ${ }^{16,19}$ A preparation of recombinant prorenin $(0.1$ or $0.5 \mathrm{nmoll}^{-1}$ ) was flown through the sensor chip at $10 \mu 1 \mathrm{~min}^{-1}$ to analyze its interaction with $s(\mathrm{P}) \mathrm{RR}$. Flow cells that were activated with EDC/NHS (1-ethyl-3(3-dimethyl-aminopropyl) carbodiimide/N-hydroxysuccinimide), treated with only buffer (HBS-EP, Hepes buffered saline) and blocked by ethanolamine were used as negative control cells. Any binding response observed in these cells was considered non-specific binding, and specific binding values were obtained after non-specific binding was subtracted from the total binding. Surface regeneration was achieved using a mixture of glycine $\left(10 \mathrm{mmoll}^{-1}\right)$ and $\mathrm{NaCl}$ $\left(150 \mathrm{mmol}^{-1}\right)$ at $\mathrm{pH} 2.0$ to avoid repeated coupling of anti-(P)RR antibodies.

\section{Basic conditions and validation parameters for the (P)RR ELISA}

The anti-237/250 antibody was conjugated to biotin using the Biotin Labeling Kit- $\mathrm{NH}_{2}$ (Dojindo, Kumamoto, Japan), according to the manufacturer's instructions, and was used as the secondary antibody in the present study. The wells of microtiter plates were coated with the primary anti-(P)RR antibody ( $\alpha$-human renin $\mathrm{R}$ polyclonal antibody) at a concentration of $100 \mathrm{ng}$ per well for at least $18 \mathrm{~h}$ at $4^{\circ} \mathrm{C}$. Antibody-coated wells were incubated at $25^{\circ} \mathrm{C}$ for $1 \mathrm{~h}$ with $100 \mu \mathrm{l}$ volumes of samples and standards. Recombinant human (P)RR was used at concentrations of $1.5,3,7.5,15,30,75,150$, 300 and $750 \mathrm{pmoll}^{-1}$ for optimizing a standard curve. After each well was washed, $100 \mu \mathrm{l}$ of biotin-labeled anti-237/250 antibody ( $\sim 5.0 \mathrm{ng}$ per well) was incubated at $25^{\circ} \mathrm{C}$ for $2 \mathrm{~h}$. Wells were washed again, and $100 \mu \mathrm{l}$ of a high-sensitivity streptavidin-horseradish peroxidase conjugate from Thermo (PIERCE, Rockford, IL, USA) was added at a dilution of 1:20000 and then incubated at $25^{\circ} \mathrm{C}$ for $2 \mathrm{~h}$. Finally, a mixture of the peroxidase substrates

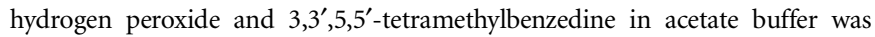
incubated at $25^{\circ} \mathrm{C}$ for $20 \mathrm{~min}$. The reaction was stopped by adding $1 \mathrm{moll}^{-1}$ $\mathrm{H}_{2} \mathrm{SO}_{4}$. The absorbance of each well was measured at $450 \mathrm{~nm}$. A total of five standard curves were determined on the same day, and coefficient of variation (CV) values were calculated as an appropriate parameter to express intraday precision (repeatability). Different concentrations $\left(1.5-750 \mathrm{pmoll}^{-1}\right)$ of synthesized (P)RR were used to determine the region of linearity. The exact linear range (7.5-300 $\mathrm{pmoll}^{-1}$ ) was reproduced. Standard curves based on triplicate experiments were determined on 5 different days, and the corresponding CVs were assessed to express interassay (interday) precision. Accuracy was expressed as the degree of agreement between the measured concentration and the theoretical concentration.

\section{Measurement of the renin activity of activated prorenin}

Prorenin at $0.1 \mathrm{nmoll}^{-1}$ was incubated with the collected HUVEC culture medium containing $32 \mathrm{pmoll}^{-1}$ of $\mathrm{s}(\mathrm{P}) \mathrm{RR}$ for $30 \mathrm{~min}$ at $25^{\circ} \mathrm{C}$. Similarly, prorenin $\left(0.1 \mathrm{nmoll}^{-1}\right)$ was also incubated with recombinant (P)RR ( $32 \mathrm{pmoll}^{-1}$, as determined by the sandwich ELISA) for $30 \mathrm{~min}$ at $25^{\circ} \mathrm{C}$ as a positive control. Activation of prorenin $\left(0.1 \mathrm{nmoll}^{-1}\right)$ by incubation with 
phosphate-buffered saline and fresh HUVEC culture medium served as the negative control. Finally, activity was calculated by subtracting negative controls (non-specific activation of prorenin in phosphate-buffered saline and fresh HUVEC medium) from total renin activity. The renin activity of prorenin was measured using recombinant sheep angiotensinogen as the substrate ${ }^{13}$ under standard assay conditions, followed by Ang-I ELISA, ${ }^{22}$ as described previously. ${ }^{13,20}$ Angiotensinogen at a concentration of $0.3 \mu \mathrm{moll}^{-1}$ was used to generate Ang-I in the presence of activated prorenin. At this concentration, the reaction rate was easily controlled, and less than $3 \%$ of the total substrate was utilized. ${ }^{20}$ The percent activation of prorenin was calculated by comparing the activity of trypsin-treated prorenin, which generated $10 \mathrm{ng}$ Ang-I per ml per $\mathrm{h}$ from $0.3 \mu \mathrm{moll}^{-1}$ angiotensinogen.

\section{RESULTS}

\section{Identification of (P)RR in HUVEC culture medium}

Western blot analysis confirmed the presence of a protein in the medium of cultured HUVECs that was recognized by antibodies directed against the epitope sequence $S^{237}$ KILVDALQKFADD ${ }^{250}$ from human $(\mathrm{P}) \mathrm{RR}$ (Figure 1a, lane 1). The molecular weight of the protein was estimated to be $\sim 30 \mathrm{kDa}$. The same protein was also identified by an antibody against another epitope sequence $\left(E^{221}\right.$ IGKRYGEDSEQFRD ${ }^{235}$ ) of (P)RR (data not shown). Surface plasmon resonance using a BIAcore assay (Figure 1b) further confirmed the presence of $(\mathrm{P}) \mathrm{RR}$ in the medium because a positive binding response to the immobilized anti-221/235 antibody (on the carboxymethyl sensor chip) was observed when flowing cultured HUVEC medium over the chip at $10 \mu \mathrm{min}^{-1}$.

Kinetics of recombinant prorenin binding to $(\mathrm{P}) \mathrm{RR}$ from cultured HUVEC medium

Using surface plasmon resonance in a BIAcore assay system, we observed binding of recombinant human prorenin to recombinant (P)RR (synthesized in vitro) with a similar $K_{\mathrm{D}}\left(1 \mathrm{nmoll}^{-1}\right)$ value as reported in our previous findings. ${ }^{16}$ Using a similar method, it was found that recombinant prorenin showed a binding response when cultured HUVEC medium was flown through the sensor chip (Figure $2 \mathrm{~b})$. The association $\left(k_{\mathrm{a}}\right)$ and dissociation $\left(k_{\mathrm{d}}\right)$ rate constants
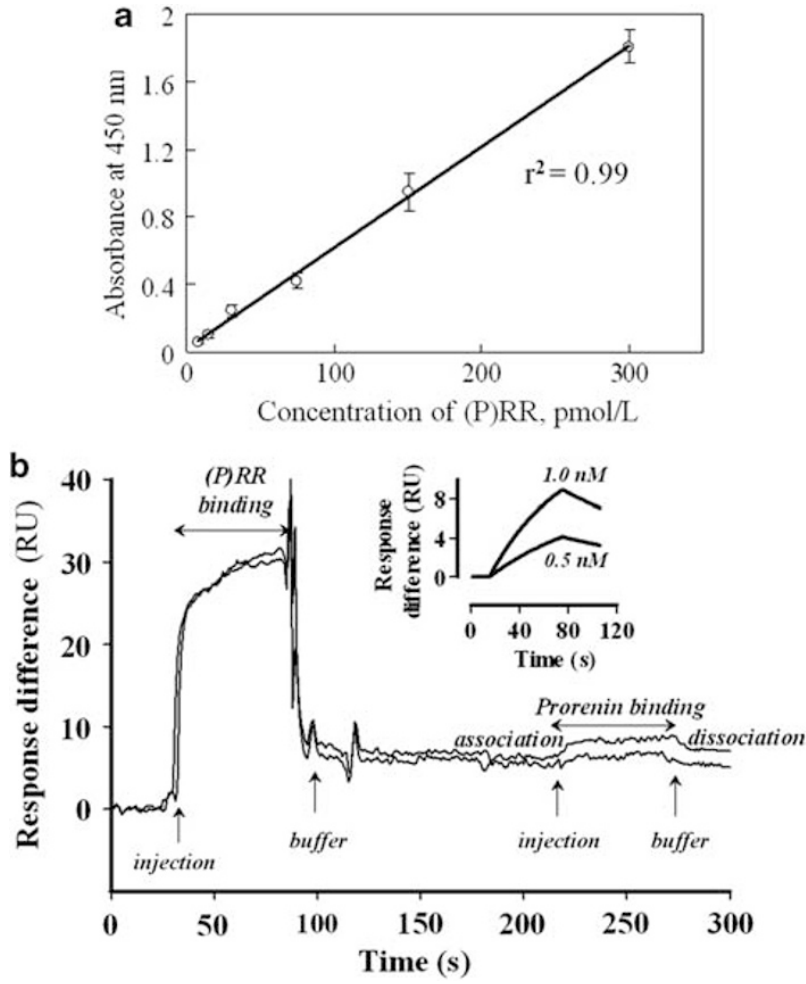

Figure 2 (a) Standard curve for determining the concentration of (pro)renin receptor. The validated standard curve shows a linear range for the quantification of soluble (P)RR, s(P)RR), from 7.5 to $300 \mathrm{pmoll}^{-1}$. (b) Realtime-binding response of prorenin to $s(P) R R$ from human umbilical vein endothelial cell (HUVEC) culture medium. Binding of $s(P) R R$ to the immobilized anti-221/235 antibody was followed by prorenin (500 and $100 \mathrm{pmoll}^{-1}$ ) binding to $\mathrm{s}(\mathrm{P}) \mathrm{RR}$. Cultured HUVEC medium $\left(30 \mathrm{pmol}^{-1}\right)$ was flown at a rate of $10 \mu \mathrm{lmin}^{-1}$. Binding responses are indicated by the response difference of resonance signals $(\mathrm{RU})$. The binding affinity $\left(K_{\mathrm{D}}\right)$ of $\mathrm{s}(\mathrm{P}) \mathrm{RR}$ (ratio of $k_{\mathrm{d}} / k_{\mathrm{a}}$ ) was determined to be $4.0 \mathrm{nmoll}^{-1}$. The inset represents a BIA simulation of prorenin binding to $\mathrm{s}(\mathrm{P}) \mathrm{RR}$.
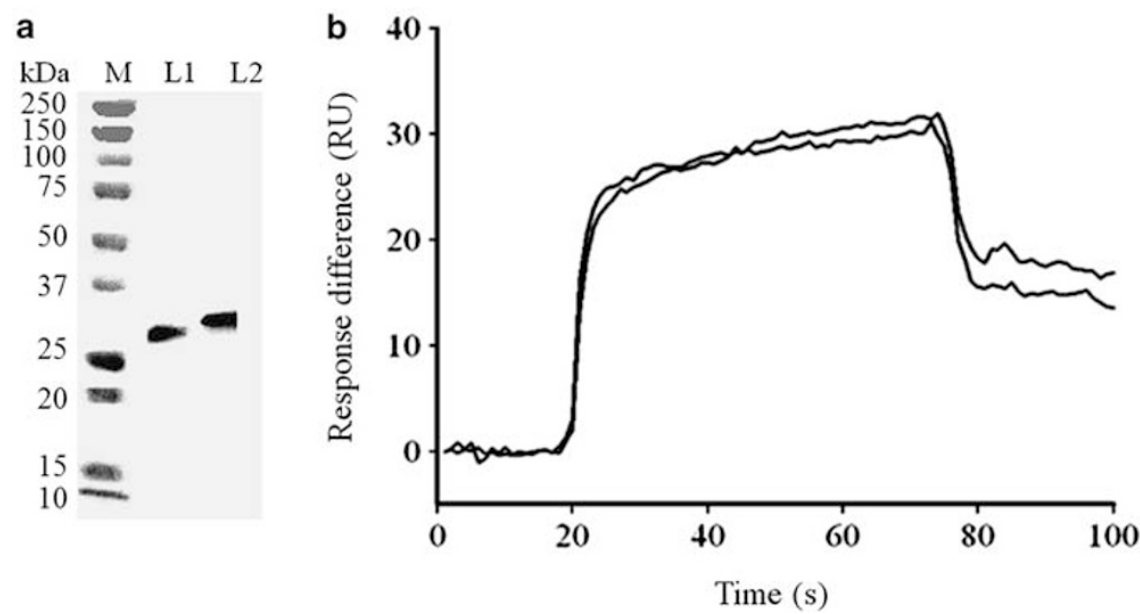

Figure 1 (a) Western blot analysis of human umbilical vein endothelial cell (HUVEC) culture medium and recombinant (P)RR synthesized in vitro. Western blot analysis confirms the presence of a 30-kDa protein in the medium of the cultured HUVECs (lane 1), identified by the anti-237-250 antibody. The band in lane 2 represents a 32.5-kDa recombinant (pro)renin receptor synthesized in vitro using wheat germ lysate, which was recognized by the anti-221/235 antibody. (b) Real-time-binding response mediated by soluble (P)RR from HUVEC culture medium. The response signal (indicated by resonance units) generated by surface plasmon resonance in a BIAcore assay system due to the interaction of the 30-kDa protein from HUVEC medium with immobilized anti-221/235 antibodies on the surface of a carboxymethyl sensor chip confirms the presence of (P)RR in the culture medium. 
Table 1 Intraassay precision and accuracy for ELISA quantification of soluble (P)RR

\begin{tabular}{lccccc}
\hline $\begin{array}{l}\text { Standard } \\
\text { code }\end{array}$ & $\begin{array}{c}\text { Theoretical } \\
\text { concentration } \\
\left(\text { pmol/-1) }^{-1}\right.\end{array}$ & $\begin{array}{c}\text { Absorbance } \\
\text { at 450 nm }\end{array}$ & $\begin{array}{c}\text { Mean of measured } \\
\text { concentration } \\
\text { (pmol/-1) }\end{array}$ & $\begin{array}{c}\text { CV } \\
\text { (\%) }\end{array}$ & $\begin{array}{c}\text { Accuracy } \\
\text { (\%) }\end{array}$ \\
\hline S1 & 7.5 & 0.06 & $8 \pm 0.208$ & 2.600 & 106 \\
S2 & 15 & 0.098 & $14 \pm 0.63$ & 4.500 & 93.3 \\
S3 & 30 & 0.24 & $37 \pm 0.925$ & 2.500 & 123 \\
S4 & 75 & 0.42 & $68 \pm 2.86$ & 4.200 & 90.6 \\
S5 & 150 & 0.95 & $155 \pm 10.85$ & 7.000 & 103 \\
S6 & 300 & 1.81 & $299 \pm 6.28$ & 2.100 & 99.6
\end{tabular}

Abbreviations: CV, coefficient of variation; ELISA, enzyme-linked immunosorbent assay; (P)RR, (pro)renin receptor.

$$
\text { Accuracy }=\frac{\text { Mean of standard concentration }\left(\mathrm{pmoll}^{-1}\right)}{\text { Theoretical concentration }\left(\mathrm{pmoll}^{-1}\right)} \times 100
$$

were $1.9 \times 10^{6}\left(1 \mathrm{~mol}^{-1}\right) \mathrm{s}^{-1}$ and $7.6 \times 10^{-3} \mathrm{~s}^{-1}$. The dissociation constant $\left(K_{\mathrm{D}}\right)$ was estimated to be $4.0 \mathrm{nmoll}^{-1}$, as calculated from the ratio of $k_{\mathrm{d}} / k_{\mathrm{a}}$.

\section{Establishment and validation of an ELISA for the measurement of} (P)RR in HUVEC culture medium

The reproducibility (intraassay precision) of the ELISA was determined by multiple measurements of standard concentrations ranging from 1.5 to $750 \mathrm{pmoll}^{-1}$. Single concentrations were varied and selected to obtain a reproducible linear concentration curve. Before optimization of the single concentrations for constructing a calibration curve, concentration below $7.5 \mathrm{pmoll}^{-1}$ (1.5 and $3.0 \mathrm{pmoll}^{-1}$ ) showed very poor reproducibility and accuracy, with a saturation phase $>300 \mathrm{pmoll}^{-1}$ (data not shown). A linear range from 7.5 to $300 \mathrm{pmoll}^{-1}$ was selected to construct the standard curve (Figure 2a). Thus, the reproducibility (repeatability) and accuracy of the ELISA were determined by multiple measurements of standard concentrations (S1-S6) from 7.5 to $300 \mathrm{pmoll}^{-1}$ (Table 1). The standard curve showed excellent linearity $\left(r^{2}=0.99\right)$ and resulted in intraassay precision $(\mathrm{CV}=2.1-7.0 \%)$ and accuracy $(90.6-123 \%)$, as shown in Table 1. The interassay (interday) precision was determined using triplicates from standard samples (7.5-300 pmoll $^{-1}$ ) on 5 different days and reached $5.8-9.7 \%$ CV. This sandwich ELISA was applied to quantify $\mathrm{s}(\mathrm{P}) \mathrm{RR}$ in the medium of cultured HUVECs. The absorbance at $450 \mathrm{~nm}$ for the measurement of $\mathrm{s}(\mathrm{P}) \mathrm{RR}$ concentration in cultured HUVEC medium was 0.125 , which fits well within the stable linear range of the standard curve. The measured concentration was around $32 \mathrm{pmoll}^{-1}$. To avoid the precipitation of (P)RR and to minimize assay interference, on the part, of surrounding proteins, the $(\mathrm{P}) \mathrm{RR}$ preparation and the cultured HUVEC medium were mixed with $3 \%$ bovine serum albumin and $0.5 \%$ Brij35, as described previously. ${ }^{16}$ However, we could not determine the levels of $(\mathrm{P}) \mathrm{RR}$ in plasma, possibly because of its concentration being too low.

\section{Catalytic activity of activated prorenin}

After recombinant prorenin was incubated with recombinant $(\mathrm{P}) \mathrm{RR}$ synthesized in vitro and $\mathrm{s}(\mathrm{P}) \mathrm{RR}$ from HUVEC culture medium, renin activity was measured to be 2.5 and $0.55 \mathrm{ng}$ Ang-I per ml per h, respectively.

\section{DISCUSSION}

This study reports the existence of an $\sim 30-\mathrm{kDa}$ protein in the medium of cultured HUVECs (Figure 1a). This protein can bind prorenin with a nanomolar-range dissociation constant $\left(K_{\mathrm{D}}\right)$, similar to what was reported for full-length $(\mathrm{P}) \mathrm{RR}$ expressed on the cell membrane $e^{1,3,4}$ or in a baculovirus expression system. ${ }^{13}$ Prorenin showed renin activity when incubated with cultured HUVEC medium at $25^{\circ} \mathrm{C}$. These primary observations led us to propose that the medium from cultured HUVECs contains (P)RR, which could be the outcome of shedding from either the cell membrane or the intracellular compartments, as suggested by Cousin et al. ${ }^{2}$ They reported an $\sim 28$ - $\mathrm{kDa}$ form of (P)RR shed from cells by furin, whereas we observed a slightly larger protein that showed (P)RR-like properties and was recognized by anti-(P)RR antibodies. In this study, we did not focus on the mechanism of release of $(\mathrm{P}) \mathrm{RR}$ into the culture medium, but rather we elucidated the prorenin binding and activation properties of this protein and established an assay system using the culture medium. The presence of this protein in the medium was further confirmed when a binding response to anti-(P)RR antibodies (anti-221/235 and anti-237/250 antibodies) was observed on carboxymethyl 5 sensor chips in a BIAcore assay when flowing $10 \mu \mathrm{min}^{-1}$ of cultured HUVEC medium into the flow cells (Figure $1 \mathrm{~b}$ ). In this case, the binding response of recombinant $(\mathrm{P}) \mathrm{RR}$ synthesized in vitro $(32.5 \mathrm{kDa}$, Figure 1a) served as supporting evidence by showing a similar binding response on the same surface used in our previous studies. ${ }^{16,19}$ In addition, a sandwich ELISA was established to determine the concentration of (P)RR. Quantification of (P)RR using ELISA showed good accuracy (90.6-123\%) and reproducibility (Table 1), and was applicable to measure the concentration of (P)RR in the medium of cultured HUVECs. This assay system also exhibited excellent CVs, indicating interassay and intraassay precision. These values were within the reasonable and acceptable range when compared with another ELISA validation protocol. ${ }^{23}$ The ELISA was highly sensitive because it could detect a picomolar level of (P)RR in the medium, and the absorbance of the samples fit well within the linear range of the standard curve (Figure 2a).

Our recent reports have revealed that recombinant human prorenin binds to recombinant (P)RR with a $K_{\mathrm{D}}$ of around $1 \mathrm{nmoll}^{-1}$, as estimated by a kinetic BIAcore assay system and equilibrium state analysis. ${ }^{16}$ In the present assay, BIAcore data showed that the $K_{\mathrm{D}}$ for the binding of prorenin to $\mathrm{s}(\mathrm{P}) \mathrm{RR}$ was $4.0 \mathrm{nmoll}^{-1}$, calculated from the ratio of dissociation rate constant $\left(k_{\mathrm{d}}=7.6 \times 10^{-3} \mathrm{~s}^{-1}\right)$ to the association rate constant $\left(k_{\mathrm{a}}=1.9 \times 10^{6}(1 \mathrm{~mol})^{-1} \mathrm{~s}^{-1}\right)$. These variations in the $K_{\mathrm{D}}$ values of prorenin for binding to $\mathrm{s}(\mathrm{P}) \mathrm{RR}$ and recombinant (P)RR might be due to their different molecular sizes, as observed by western blot analysis (Figure 1a). In this study, when incubated with recombinant $(\mathrm{P}) \mathrm{RR}$, recombinant prorenin showed renin activity. This result indicates $(\mathrm{P}) \mathrm{RR}$-mediated activation of prorenin in the solution. Whether prorenin was activated non-proteolytically was investigated by western blot analysis, and a similar immigration distance was observed in the case of activated prorenin and native wild-type prorenin using an antiprosegment antibody (data not shown). Similarly, s(P)RR from the cultured HUVEC medium activated prorenin. Based on the $K_{\mathrm{D}}$ values, approximately four times more recombinant $(\mathrm{P}) \mathrm{RR}$-prorenin complex would form compared with the $s(\mathrm{P}) \mathrm{RR}$-prorenin complex under the same concentration of prorenin $\left(0.1 \mathrm{nmoll}^{-1}\right)$ and the same concentration of each type of (P)RR $\left(32 \mathrm{pmoll}^{-1}\right)$. This difference was reflected by the level of activation of prorenin by $(\mathrm{P}) \mathrm{RR}$. These results further indicate that once prorenin is bound to the $(\mathrm{P}) \mathrm{RR}$, it becomes non-proteolytically activated and expresses full renin activity. Renin activities were measured to be 2.5 and $0.55 \mathrm{ng}$ Ang-I per ml per h, which were 25 and $5.5 \%$ of the activity attained by trypsin-treated prorenin at a concentration of $0.1 \mathrm{nmoll}^{-1}$ (10 ng Ang-I per ml per h). 
Therefore, this study reports the development and optimization of a sandwich ELISA for the quantitative measurement of $s(P) R R$ in HUVEC culture medium. Moreover, this study investigated the binding of $s(\mathrm{P}) \mathrm{RR}$ in HUVEC culture medium to human prorenin and its activation of prorenin.

\section{CONFLICT OF INTEREST}

The authors declare no conflict of interest.

\section{ACKNOWLEDGEMENTS}

This study was supported, in part, by a Grant-in-aid for Scientic Research (1907165) from the Ministry of Education, Science and Culture of Japan and an NIH grant (HL58205).

1 Nguyen G, Delarue F, Burckle C, Bouzhir L, Giller T, Sraer JD. Pivotal role of the renin/ prorenin receptor in angiotensin II production and cellular responses to renin. J Clin Invest 2002; 109: 1417-1427.

2 Cousin C, Bracquart D, Contrepas A, Corvol P, Muller L, Nguyen G. Soluble form of the (pro)renin receptor generated by intracellular cleavage by furin is secreted in plasma. Hypertension 2009; 53: 1077-1082.

3 Batenburg WW, Krop M, Garrelds IM, de Vries R, de Bruin RJ, Burcklé CA, Müller DN, Bader M, Nguyen G, Danser AHJ. Prorenin is the endogenous agonist of the (pro)renin receptor, binding kinetics of renin and prorenin in rat vascular smooth muscle cells overexpressing the human (pro)renin receptor. J Hypertens 2007; 25: 2441-2453.

4 Nurun NA, Uddin MN, Nakagawa T, Iwata H, Ichihara A, Inagami T, Suzuki F. Role of 'handle' region of prorenin prosegment in the non-proteolytic activation of prorenin by binding to membrane anchored (pro)renin receptor. Front Biosci 2007; 12: 4810-4817.

5 Biswas KB, Nabi AHMN, Arai Y, Nakagawa T, Ebihara A, Suzuki F. Species specificity of prorenin binding to the (pro)renin receptor in vitro. Front Biosci 2010; E2 1234-1240.

6 Sakoda M, Ichihara A, Kaneshiro Y, Takemitsu T, Nakazato Y, Nabi AHMN, Nakagawa T, Suzuki F, Inagami T, Itoh $\mathrm{H}$. (Pro)renin receptor-mediated activation of mitogenactivated protein kinases in human vascular smooth muscle cells. Hypertens Res 2007; 30: 1139-1146.

7 Ichihara A, Sakoda M, Mito-Karauchi A, Itoh H. Activated prorenin as therapeutic target for diabetic nephropathy. Diab Res Clin Prac 2008; 825: S63-S66.

8 Satofuka S, Ichihara A, Nagai N, Tsubota K, Itoh H, Ishida S. Pathologic roles of prorenin and (pro)renin receptor in the eye. Front Biosci 2008; 13: 3884-3895.

9 Ichihara A, Kaneshiro Y, Takemitsu T, Sakoda M, Suzuki F, Nakagawa T, Nishiyama A, Inagami T, Hayashi M. Nonproteolytic activation of prorenin contributes to development of cardiac fibrosis in genetic hypertension. Hypertension 2006; 47 : 894-900.

10 Burcklé CA, Bader M. Prorenin and its ancient receptor. Hypertension 2006; 48 : 549-551.

11 Kaneshiro Y, Ichihara A, Sakoda M, Takemitsu T, Nabi AHMN, Uddin MN, Nakagawa T, Nishiyama A, Suzuki F, Inagami T, Itoh T. Slowly progressive, angiotensin II-independent glomerulosclerosis in human (pro)renin receptor-transgenic rats. J Am Soc Nephrol 2007; 18: 1789-1795.

12 Ramser J, Abidi FE, Burckle C, Lenski C, Toriello H, Wen G, Lubs HA, Engert S, Stevenson RE, Meindl A, Schwartz CE, Nguyen G. A unique exonic splice enhancer mutation in a family with $X$-linked mental retardation and epilepsy points to a novel role of the renin receptor. Hum Mol Genet 2005; 14: 1019-1027.

13 Nabi AHMN, Kageshima A, Uddin MN, Nakagawa T, Park EY, Suzuki F. Binding properties of rat prorenin and renin to the recombinant rat renin/prorenin receptor prepared by a baculovirus expression system. Int J Mol Med 2006; 18: 483-488.

14 Kato T, Kageshima A, Suzuki F, Park EY. Expression and purification of human (pro)renin receptor in insect cells using baculovirus expression system. Prot Expr Purif 2008; 58: 242-248.

15 Du D, Kato T, Nabi AHMN, Suzuki F, Park EY. Expression of functional human (pro)renin receptor in silkworm (Bombyx mori) larvae using BmMNPV bacmid. Biotechnol Appl Biochem 2008; 49: 195-202.

16 Nabi AHMN, Biswas KB, Nakagawa T, Ichihara A, Inagami T, Suzuki F. Prorenin has high affinity multiple binding sites for (pro)renin receptor. Biochim Biophys Acta 2009; 1794: 1838-1847.

17 Leckie BJ, Bottrill AR. A specific binding site for the prorenin propart peptide Arg10Arg20 does not occur on human endothelial cells. J Renin Angiotensin Aldosterone Syst 2010; (in press).

18 Uraoka M, Ikeda K, Nakagawa Y, Koide M, Akakabe Y, Nakano-Kurimoto R, Takahashi T, Matoba S, Yamada H, Okigaki M, Matsubara H. Prorenin induces ERK activation in endothelial cells to enhance neovascularization independently of the rennin-angiotensin system. Biochem Biophys Res Commun 2009; 390: 1202-1207.

19 Nabi AHMN, Biswas KB, Nakagawa T, Ichihara A, Inagami T, Suzuki F. 'Decoy peptide' region (RIFLKRMPSI) of prorenin prosegment plays a crucial role in prorenin binding to the (pro)renin receptor. Int J Mol Med 2009; 24: 83-89.

20 Biswas KB, Nabi AHMN, Arai Y, Nakagawa T, Ebihara A, Ichihara A, Watanabe T, Inagami T, Suzuki F. Aliskiren binds to renin and prorenin bound to (pro)renin receptor in vitro. Hypertens Res 2010; 33: 1053-1059.

21 Nakagawa T, Nishiuchi K, Akaki J, Iwata H, Satou R, Suzuki F, Nakamura Y. Efficient production of recombinant human (pro)renin utilizing a decahistidine tag attached at the C-terminus. Biosci Biotechnol Biochem 2007; 71: 256-260.

22 Suzuki F, Yamashita S, Takahashi A, Ito M, Miyazaki S, Nagata Y, Nakamura Y. Highly sensitive microplate-ELISA for angiotensin I using 3,3',5,5'- tetramethylbenzidine. Clin Exp Hypertens A 1990; 12: 83-95.

23 Standker L, Zackgo V, Hillemanns $P$, Rosinger M, Forssmann WG, Hass R. Quantitative enzyme-linked immunosorbent assay determination of an abundant hemoglobin-derived anti-infective peptide in human placenta. Anal Biochem 2010; 401: 53-60. 